\title{
Endocarditis infecciosa de la válvula tricúspide asociada con meningitis aséptica: presentación infrecuente en una niña
} Tricuspid valve infective endocarditis associated with aseptic meningitis: a rare presentation in a child

\author{
Dra. Gülsüm Alkan ${ }^{a}$ Prof. Asist. Dra. Melike Emiroğlua, Prof. Asoc. Dr. Ahmet Sert ${ }^{b}$, \\ Prof. Asoc. Dra. Ayşe Kartalc y Prof. Dr. Mehmet Öc $c^{d}$
}

\begin{abstract}
RESUMEN
La endocarditis infecciosa es infrecuente pero potencialmente mortal. Las presentaciones atípicas retrasan el diagnóstico. El compromiso neurológico es habitual en la endocarditis de la válvula mitral, aunque infrecuente en la endocarditis de la válvula tricúspide. Si bien se han informado algunos casos e el del lado derecho con síntomas neurológicos en adultos, en la bibliografía no se ha descripto en niños. Se presenta una niña de 9 años con comunicación interventricular (CIV) congénita con fiebre, cefalea y rigidez de nuca. Sus síntomas clínicos y los hallazgos en el líquido cefalorraquídeo respaldaron el diagnóstico de meningitis aséptica. El día 3 del tratamiento con ceftriaxona, se resolvieron los síntomas; tras nueve días, reingresó con fiebre y rigidez de nuca. Un ecocardiograma mostró endocarditis de la válvula tricúspide. Recibió tratamiento antibiótico durante6 semanas. Se realizó una cirugía cardíaca para la CIV y la insuficiencia de la válvula tricúspide. Palabras clave: meningitis aséptica, endocarditis infecciosa, insuficiencia tricuspídea, comunicación interventricular, niños.
\end{abstract}

http: / / dx.doi.org/10.5546/ aap.2020.e22

Texto completo en inglés:

http:/ / dx.doi.org/10.5546/ aap.2020.eng.e22

Cómo citar: Alkan G, Emiroğlu M, Sert A, Kartal A, Öc M. Endocarditis infecciosa de la válvula tricúspide asociada con meningitis aséptica: presentación infrecuente en una niña. Arch Argent Pediatr 2020;118(1):e22-e25.

a. Departamento de Enfermedades Infecciosas Pediátricas.

b. Departamento de Cardiología Pediátrica.

c. Departamento de Neurología Pediátrica.

d. Departamento de Cirugía Cardiovascular.

Facultad de Medicina de Selçuk Üniversitesi, Konya,

Turquía.

Correspondencia:

Dra. Gülsüm Alkan: galkan-85@hotmail.com

Financiamiento: Ninguno.

Conflicto de intereses: Ninguno que declarar.

Recibido: 9-12-2018

Aceptado: 19-7-2019

\section{INTRODUCCIÓN}

La endocarditis infecciosa (EI) es una enfermedad infecciosa potencialmente mortal del endocardio o las válvulas cardíacas. Si bien es poco frecuente en los niños, el diagnóstico temprano es importante debido a las elevadas tasas de morbimortalidad. ${ }^{1}$ Aproximadamente del $35 \%$ al $60 \%$ de los niños con diagnóstico de EI tienen cardiopatías congénitas (CC). La comunicación interventricular (CIV), el conducto arterial persistente, la válvula aórtica bicúspide y la tetralogía de Fallot son factores de alto riesgo de EI. Los niños con CC podrían presentar endocarditis a cualquier edad, más frecuentemente del lado izquierdo. La endocarditis infecciosa del lado derecho es relativamente infrecuente $y$, a menudo, afecta la válvula tricúspide. Ocurre principalmente en los usuarios de drogas intravenosas y en las personas con catéteres y otros dispositivos intravasculares. ${ }^{1,2}$

El diagnóstico de EI se basa en la obtención detallada de los antecedentes, el examen físico, hemocultivos repetidos y un ecocardiograma. Los nódulos de Osler, las hemorragias subungueales, las manchas de Roth y las lesiones de Janeway son signos clínicos poco frecuentes pero específicos de la EI. Un factor de riesgo de endocarditis y la aparición de un soplo en un niño febril permiten realizar un diagnóstico temprano. Los principales microorganismos causales en los niños son los estreptococos, los estafilococos y los enterococos. La manifestación más común es la insuficiencia cardíaca causada por vegetación en la válvula aórtica o mitral. ${ }^{3,4}$

Las complicaciones de la EI pueden ser cardíacas, neurológicas, renales, musculoesqueléticas y pulmonares, así como relacionadas con embolización, infección metastásica y aneurisma micótico. ${ }^{5}$

Las secuelas neurológicas son las complicaciones no cardíacas más frecuentes de la EI, principalmente, accidente cerebrovascular. Si bien las complicaciones neurológicas se presentan 
en el $25 \%$ al $70 \%$ de los pacientes adultos, no se han descripto tanto en los niños. El diagnóstico temprano, la antibioticoterapia y la cirugía son los pilares del tratamiento. ${ }^{6}$

\section{A PROPÓSITO DE UN CASO}

Se hospitalizó a una niña de 9 años con fiebre y cefalea durante dos días. Estaba en seguimiento por una CIV congénita pequeña (diámetro de $3 \mathrm{~mm}$ ). No tenía antecedentes de procedimientos odontológicos o quirúrgicos. En el examen físico, se observó temperatura corporal: $38,5^{\circ} \mathrm{C}$, frecuencia respiratoria: $20 / \mathrm{min}$, pulso: $110 / \mathrm{min}$, presión arterial: 100/60 mmHg. También se notó un soplo holosistólico intenso en el borde inferior izquierdo del esternón y signos de rigidez de nuca y de Kernig positivos. La niña no presentó otras características relevantes. No tenía hemorragias subungueales, esplenomegalia ni deficiencia neurológica focal obvia.

Los datos de laboratorio fueron los siguientes: recuento de leucocitos $17000 / \mathrm{mm}^{3}$; neutrófilos $93 \%$; linfocitos $5 \%$; hemoglobina $12,7 \mathrm{~g} / \mathrm{dl}$; trombocitos $225000 / \mathrm{mm}^{3}$; velocidad de sedimentación globular (VSG) $40 \mathrm{~mm} / \mathrm{h}$ y proteína C-reactiva $10 \mathrm{mg} / \mathrm{dl}$. El recuento del líquido cefalorraquídeo (LCR) fue de
22 neutrófilos $/ \mathrm{mm}^{3}$, 66 linfocitos $/ \mathrm{mm}^{3}$, contenido de proteínas de $26 \mathrm{mg} / \mathrm{dl}$ y de glucosa de $61 \mathrm{mg} /$ dl. La resonancia magnética no presentaba particularidades. Se inició la administración de ceftriaxona debido a la sospecha de meningitis tras una punción lumbar. Hacia el día 3 de la hospitalización, los síntomas se habían resuelto por completo.

Una vez que se obtuvieron resultados negativos en la tinción de Gram del LCR, el panel PCR para meningitis bacteriana/viral, el hemocultivo y el urocultivo, se interrumpió la ceftriaxona y la paciente recibió el alta el día 7. Dos días más tarde, volvió a ingresar con fiebre (39,5 ${ }^{\circ} \mathrm{C}$ ) y rigidez de nuca. Los análisis de laboratorio mostraron lo siguiente: leucocitos $25000 / \mathrm{mm}^{3}$ (92\% de neutrófilos con granulaciones tóxicas), hemoglobina $11 \mathrm{~g} / \mathrm{dl}$, trombocitos $216000 / \mathrm{mm}^{3}$, VSG $55 \mathrm{~mm} / \mathrm{h}$ y proteína C-reactiva $16 \mathrm{mg} / \mathrm{dl}$. En el examen físico, no se halló el origen obvio de la fiebre. La familia se rehusó al examen del LCR. Se realizó un ecocardiograma para detectar el origen de la fiebre y se halló endocarditis de la válvula tricúspide con vegetación $(10,7 \mathrm{~mm}$ x 6,6 mm; Figura 1) y CIV (diámetro de $3 \mathrm{~mm}$; clip de video 1) con derivación de izquierda a derecha. La tomografía computada del cráneo

FIGURA 1. Ecocardiograma transtorácico que muestra vegetación en la válvula tricúspide. Vegetación, con un diámetro de aproximadamente 10,7 $\mathrm{mm} \times 6,6 \mathrm{~mm}$, anexa a la valva septal de la válvula tricúspide

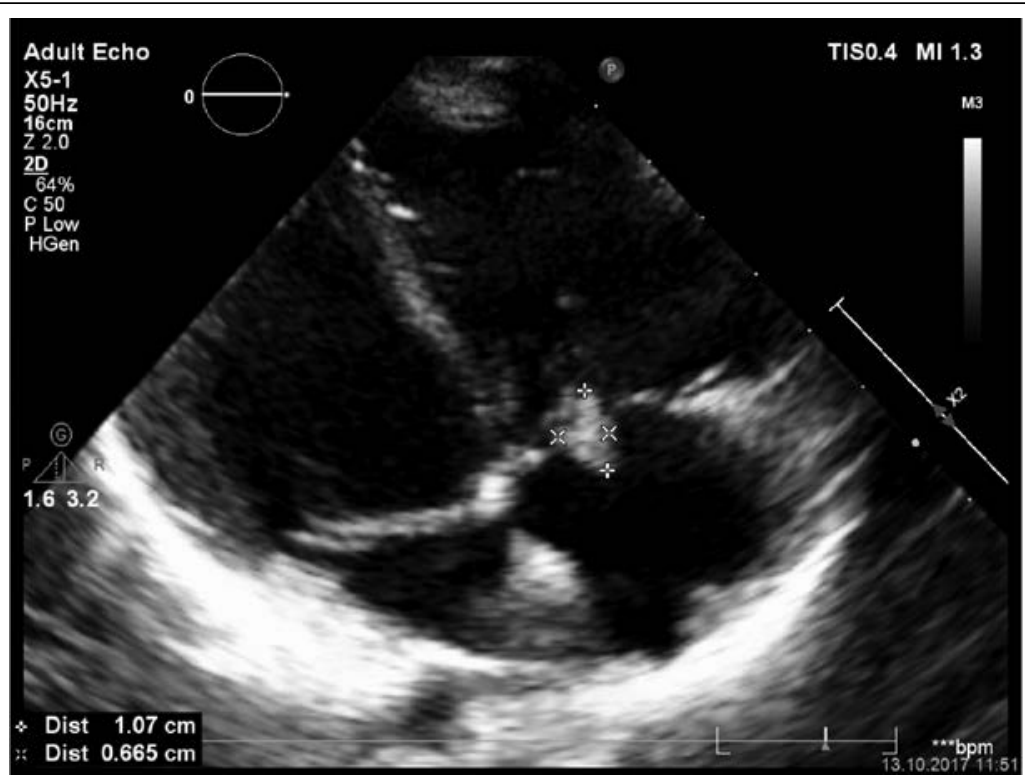

CLIP DE VIDEO 1. Comunicación interventricular (diámetro de $3 \mathrm{~mm}$ )

Link: http: / / www.sap.org.ar/uploads/archivos /general/files_855-moving-video_1mp4_1565371460.mp4 
fue normal. Según el seguimiento, la rigidez de nuca se resolvió en el transcurso de 24 horas. Dos hemocultivos consecutivos fueron positivos para Staphylococcus aureus sensible a la meticilina. Se inició la administración de teicoplanina y gentamicina. La vegetación en la válvula tricúspide causaba insuficiencia valvular, por lo que se la removió mediante cirugía cardíaca con circulación extracorpórea, incluida una valvuloplastía tricus pídea cuatro semanas después.

Se interrumpieron los antibióticos tras seis semanas, una vez que los hemocultivos fueron negativos durante dos semanas. La paciente recibió el alta con insuficiencia tricuspídea leve residual. Durante el año que duró el seguimiento, no presentó síntomas.

\section{DISCUSIÓN}

Las complicaciones neurológicas de la EI estuvieron significativamente asociadas con vegetaciones por S. aureus y, con frecuencia, son el resultado de la embolización de la vegetación en la válvula aórtica o mitral. Los eventos isquémicos o hemorrágicos, la sepsis, la meningitis y la vasculitis cerebral son afecciones clínicas frecuentes. Los múltiples émbolos sépticos podrían causar absceso cerebral o meningoencefalitis, caracterizada por fiebre, cefalea y meningismo. Se estima que la frecuencia de la meningitis aséptica o bacteriana como complicación de la EI es del 3,5 \%. En general, la meningitis suele ser purulenta si está asociada con microorganismos virulentos, como S. aureus. El LCR podría presentar una fórmula aséptica cuando está asociado con hemorragia subaracnoidea o embolismos microscópicos múltiples. ${ }^{78}$ A pesar del uso de antibióticos, la mortalidad sigue siendo elevada. Las complicaciones neurológicas podrían requerir cirugía cardíaca. ${ }^{9}$

La endocarditis del lado derecho representa el $10 \%$ de todos los casos de EI. La presentación más frecuente incluye fiebre persistente, bacteriemia, émbolos pulmonares múltiples, infarto pulmonar e insuficiencia cardíaca derecha. Lamblin y col. informaron sobre un niño de 8 años con endocarditis infecciosa de la válvula tricúspide que tenía abscesos pulmonares múltiples, neumotórax y osteoartritis. ${ }^{10}$ En la presencia de CIV, pueden verse vegetaciones en el lado ventricular derecho de la comunicación o en la válvula tricúspide. A diferencia de la endocarditis del lado izquierdo, no suelen presentarse manifestaciones neurológicas ni embólicas periféricas. Si se presentan estas manifestaciones, se debe considerar la endocarditis del lado izquierdo o la embolia paradójica. Si bien se han informado algunos casos de EI del lado derecho con síntomas neurológicos en los adultos, en la bibliografía no se ha descripto su manifestación en los niños. Lucas y cols. informaron sobre 24 pacientes adultos diagnosticados con endocarditis infecciosa y meningitis bacteriana. Solo un paciente tenía endocarditis de la válvula tricúspide y meningitis por $S$. aureus. ${ }^{11-13}$

La antibioticoterapia exclusiva podría ser insuficiente en la EI. Debe considerarse la cirugía en caso de insuficiencia cardíaca, bacteriemia persistente refractaria al tratamiento, insuficiencia valvular grave, presencia de vegetaciones importantes o fenómenos embólicos mayores. ${ }^{14}$

Hasta donde sabemos, no se ha informado sobre EI del lado derecho con signos meníngeos en niños. Nuestra paciente ingresó con signos clínicos de meningitis aséptica, pero no presentó déficit neurológico, y no se observaron indicios de embolización séptica en los estudios de diagnóstico por imágenes del cráneo. La fiebre recurrente y la cardiopatía congénita conocida, junto con el ecocardiograma, conducen al diagnóstico de EI. En nuestra paciente, se consideró que la meningitis aséptica era resultado de los émbolos pequeños, la inflamación de las estructuras parameníngeas o la baja carga bacteriana del LCR asociada con embolización paradójica. Los signos neurológicos inespecíficos, como la cefalea, con fiebre podrían ser el primer indicio de EI. Se debe realizar un ecocardiograma oportunamente para descartar la EI en los niños con fiebre sin explicación, en especial si tienen cardiopatía congénita. El diagnóstico y el tratamiento tempranos son importantes para minimizar las morbilidades cardíacas y neurológicas.

\section{REFERENCIAS}

1. Rosenthal LB, Feja KN, Levasseur SM, Alba LR, et al. The changing epidemiology of pediatric endocarditis at a children's hospital over seven decades. Pediatr Cardiol. 2010; 31(6):813-20.

2. Marom D, Ashkenazi S, Samra Z, Birk E. Infective endocarditis in previously healthy children with structurally normal hearts. Pediatr Cardiol. 2013; 34(6):1415-21.

3. Sun LC, Lai CC, Wang CY, Wang YH, et al. Risk factors for infective endocarditis in children with congenital heart diseases - A nationwide population-based case control study. Int J Cardiol. 2017; 248:126-30.

4. Singh $\mathrm{Y}$, Ganjoo N. Infective endocarditis in children. Paediatr Child Health (Oxford). 2017; 27(2):68-74.

5. Mocchegiani R, Nataloni M. Complications of infective 
endocarditis. Cardiovasc Hematol Disord Drug Targets. 2009; 9(4):240-8

6. Venkatesan C, Wainwright MS. Pediatric endocarditis and stroke: a single-center retrospective review of seven cases. Pediatr Neurol. 2008; 38(4):243-7.

7. Venkatesan A, Spalding C, Speedie A, Sinha G, Rumbaugh JA.Pseudomonas aeruginosa infective endocarditis presenting as bacterial meningitis. J Infect. 2005; 51(4):e199-202.

8. Aminoff MJ, Josephson SA. Neurological complications of systemic disease: adults. En: Daroff R, Jankovic J, Mazziotta J, Pomeroy S. Bradley's Neurology in Clinical Practice. $7^{\text {th }}$ ed. Philadelphia, PA: Elsevier Saunders; 2015.Págs.814-34.e1.

9. Heiro M, Nikoskelainen J, Engblom E, Kotilainen E, et al. Neurologic manifestations of infective endocarditis: a 17-year experience in a teaching hospital in Finland. Arch Intern Med. 2000; 160(18):2781-7.
10. Lamblin A, Derkenne C. A child with fever, cough and Lancisi's sign. Pan Afr Med J. 2018; 8;30:14.

11. Moss $R$, Munt B. Injection drug use and right sided endocarditis. Heart. 2003; 89(5):577-81.

12. Lucas MJ, Brouwer MC, van der Ende A, van de Beek D. Endocarditis in adults with bacterial meningitis. Circulation. 2013; 127(20):2056-62.

13. Williams LS, Allen BL. Neurolojic manifestations in Infective Endocarditis. En: Aminoff MJ, Josephson SA (eds). Aminoff's Neurology and General Medicine. $5^{\text {th }}$ ed. London: Elsevier; 2014.Págs.99-117.

14. Escarrá F, Fedullo AG, Veliz N, Rosa J, et al. Endocarditis por Streptococcus pneumoniae en pediatría: presentación de un caso clínico. Rev Chil Pediatr. 2017; 88(6):776-80. 